\title{
Clint M. Alfaro wins ABC Best Paper Award
}

\author{
Nicola Oberbeckmann-Winter ${ }^{1}$ (D)
}

Published online: 17 May 2017

(C) Springer-Verlag Berlin Heidelberg 2017

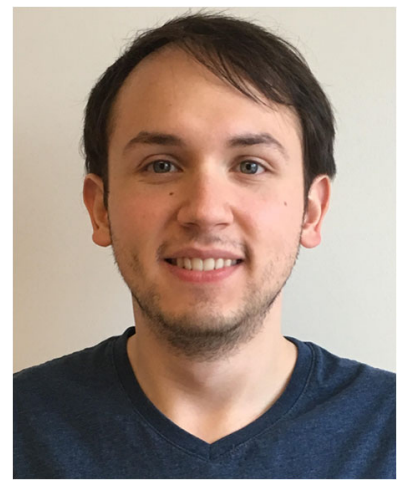

Clint M. Alfaro is a PhD candidate in analytical chemistry at Purdue University under the supervision of Henry B. Hass Distinguished Professor of Chemistry R. Graham Cooks. Clint was born January 26, 1992, and grew up in Winston-Salem, NC, USA. He graduated with honors and a B.S. in Biochemistry and Biology from the University of North Carolina, Greensboro, in 2014. His current research focuses on applications of and method development in the rapid disease-state characterization of surgical biopsy specimens with ambient ionization MS.

The ABC Best Paper Award 2016 for outstanding work published in Analytical and Bioanalytical Chemistry (ABC) goes to Clint M. Alfaro (25), who is author of the paper "Ambient ionization mass spectrometric analysis of human surgical specimens to distinguish renal cell carcinoma from healthy renal tissue," which describes molecular techniques - in particular, mass spec-

Nicola Oberbeckmann-Winter

nicola.oberbeckmann-winter@springer.com

1 Analytical and Bioanalytical Chemistry, Springer, Tiergartenstrasse 17, 69121 Heidelberg, Germany

trometry - that have great potential to augment the surgeon's toolbox. Such techniques could guide surgical decision-making during tumor resection, thus benefiting patient outcomes.

Accompanied by 1500 euros, the award is sponsored by Springer to honor exceptional young scientists and to stimulate their research careers. The article "Ambient ionization mass spectrometric analysis of human surgical specimens to distinguish renal cell carcinoma from healthy renal tissue" by Clint M. Alfaro, Alan K. Jarmusch, Valentina Pirro, Kevin S. Kerian, Timothy A. Masterson, Liang Cheng, and R. Graham Cooks is freely available online at http://link.springer.com/article/10. 1007/s00216-016-9627-4 or can be requested as a PDF.

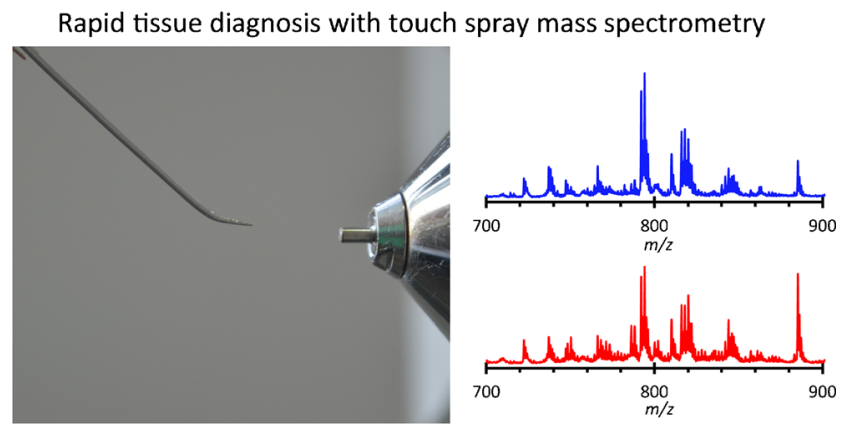

\section{Who is Clint M. Alfaro?}

Clint M. Alfaro talks about his research, his motivations, and about himself to Nicola Oberbeckmann-Winter.

What was your motivation to do research on touch spraymass spectrometry and its intraoperative applications?

The goal was to develop an analytical tool that could provide an objective assessment of disease state from a piece of tissue. Touch spray-mass spectrometry is a prime candidate because 
the technique is simple, rapid, and has demonstrated good performance in the present work and in a previous study with prostate cancer. The technique could be used by surgeons to test tissue for residual tumor, which is a primary concern when treating cancer surgically.

Why do you think your work merits the ABC Best Paper Award?

The analysis of fresh renal tissue by touch spray-mass spectrometry represents a significant step towards integrating molecular measurements by ambient ionization mass spectrometry into a method for evaluating the amount of residual tumor left in a resection cavity.

\section{How does this award-winning work relate to your PhD} research?

$\mathrm{My} \mathrm{PhD}$ thesis focuses on molecular tissue diagnostics with ambient ionization mass spectrometry. The publication (Alfaro CM, Jarmusch AK, Pirro V et al. Anal Bioanal Chem. 2016;408:5407. doi:10.1007/s00216-016-9627-4) fits exactly into this work, and brings the goal of integrating mass spectrometry into surgery a step closer by showing that touch spray-mass spectrometry is amenable to fresh tissue analysis.

\section{How would you explain your research to children?}

Cancer is a disease that can take over the body and stop it from working correctly. If doctors catch the cancer early, they can stop it from taking over by cutting it out of the body. During surgery, it is sometimes difficult for doctors to tell whether something is cancer or normal just by looking at it. My research focuses on developing new tools that doctors can use during surgery to test whether tissue is cancer or normal. These new tools can help the doctor completely cut out the cancer, making the patients live longer and potentially curing them of the disease.

\section{What's the trickiest problem you had to overcome in that research? How did you solve it?}

The trickiest problems have arisen from analytical chemists trying to perform clinical research in surgery. This problem could not have been solved without the keen cooperation of our clinical collaborators and their teams of research coordinators. This is especially true given that we have moved chemical analysis into the operating room.

Where do you see your field headed, and how do you see it influencing bioanalytical research?

I see the field moving closer and closer to directly affecting patient care. The most exciting prospect is the possibility of extracting information about patient prognosis and outcome that is hidden deep in the data and, in particular, correlating this with genetic information, which could significantly affect patient prognosis. After analyzing tissues from many more patients, especially in controlled clinical trials, who knows what other knowledge will be gained that can help to cure cancer?

Which incident/discovery has proved most valuable for your own research?

Ambient ionization mass spectrometry, one of the many great results from Prof. R. Graham Cooks, is the reason my $\mathrm{PhD}$ work has been possible.

Which incident/discovery most inspired you during your education and scientific career?

My personal discovery of the far-reaching capabilities of mass spectrometry for studying biological systems has been most inspiring.

Which recent discovery might prove most valuable to the field of (bio)analytical research or beyond?

Mini mass spectrometers coupled with ambient ionization for point of care diagnostics could revolutionize patient care.

\section{What was the best/worst advice you ever received?}

I have received great advice from my undergraduate advisor, Prof. Nadja Cech, who urged me to pursue graduate studies in mass spectrometry.

Whom do you admire the most or who inspired you the most and why?

I most admire my PhD advisor, Prof. R. Graham Cooks, for his tireless dedication to the field of mass spectrometry. He has made significant contributions to mass spectrometry, and it is amazing that he continues to lead successful projects in so many areas, ranging from fundamentals and instrumentation to chemical synthesis and clinical chemistry.

\section{What are your future plans?}

I plan to pursue a career as a chemistry research faculty member and translational scientist at a public university/medical school.

\section{What do you do in your spare time?}

My spare time is spent in the kitchen cooking, walking in parks, playing video games, and playing with my two cats. 